Meta

Journal des traducteurs

Translators' Journal

\title{
Towards a Methodology for a Corpus-Based Approach to Translation Evaluation
}

\section{Lynne Bowker}

Volume 46, numéro 2, juin 2001

Évaluation : paramètres, méthodes, aspects pédagogiques / Evaluation: Parameters, Methods, Pedagogical Aspects

URI : https://id.erudit.org/iderudit/002135ar

DOI : https://doi.org/10.7202/002135ar

Aller au sommaire du numéro

Éditeur(s)

Les Presses de l'Université de Montréal

ISSN

0026-0452 (imprimé)

1492-1421 (numérique)

Découvrir la revue

Citer cet article

Bowker, L. (2001). Towards a Methodology for a Corpus-Based Approach to Translation Evaluation. Meta, 46(2), 345-364. https://doi.org/10.7202/002135ar
Résumé de l'article

L'évaluation d'un texte traduit est probablement l'une des tâches les plus difficiles qui soit pour le professeur de traduction, et il y a peu de chances qu'une formule miracle simplifie un jour celle-ci. Le présent article laisse toutefois entrevoir un début de solution, qui consisterait à se servir d'un " corpus d'évaluation » comme norme de référence à laquelle comparer les choix traductionnels des étudiants. 


\title{
Towards a Methodology for a Corpus-Based Approach to Translation Evaluation
}

\author{
LYNNE BOWKER \\ University of Ottawa, Ottawa, Canada
}

\begin{abstract}
RÉSUMÉ
L'évaluation d'un texte traduit est probablement l'une des tâches les plus difficiles qui soit pour le professeur de traduction, et il y a peu de chances qu'une formule miracle simplifie un jour celle-ci. Le présent article laisse toutefois entrevoir un début de solution, qui consisterait à se servir d'un «corpus d'évaluation» comme norme de référence à laquelle comparer les choix traductionnels des étudiants.
\end{abstract}

\begin{abstract}
Translation evaluation is undoubtedly one of the most difficult tasks facing a translator trainer. It is unlikely that there will ever be a ready-made formula that will transform this task into a simple one; however, this article suggests that the task can be made somewhat easier by using a specially designed Evaluation Corpus that can act as a benchmark against which translator trainers can compare student translations.
\end{abstract}

\section{MOTS-CLÉS/KEYWORDS}

translation evaluation, corpus-based approach, Evaluation Corpus, student translation, corpus analysis

\section{Introduction}

This article aims to present a practical and objective approach to translation evaluation, particularly the evaluation of specialized translations in the context of translator training, based on the use of electronic corpora. In the past, translators and trainers have had to work with conventional resources (e.g. dictionaries, printed parallel texts, subject field experts, unverified intuition) which are not always highly conducive to providing the conceptual and linguistic knowledge necessary to objectively evaluate a translation. Therefore, many translations were assessed in a relative vacuum - a situation that is particularly untenable in a translation classroom, where trainers are responsible not only for grading students' work, but perhaps more importantly for providing useful feedback. It is only relatively recently that advances in computer technology have resulted in the development of resources and tools, such as electronic corpora and corpus analysis software, which can be used to facilitate a more practical and objective approach to translation evaluation. The corpus-based approach makes the task of translation evaluation somewhat less difficult by removing a great deal of the subjectivity, and by providing the translator trainer with improved access to the appropriate conceptual and linguistic information of a specialized subject field as documented by experts in that field. In short, a specially designed Evaluation Corpus can act as a benchmark against which translator trainers can compare student translations on a number of different levels. By having access to a wide range of authentic and suitable texts, the trainer can verify or correct the students' choices, 
both conceptual and linguistic, and can provide more constructive feedback based on the evidence (or indeed, on the lack of evidence) in the corpus. Moreover, students benefit more from, and are more receptive to, this type of concrete and objective feedback because they can see for themselves that it is based on corpus evidence and not merely on the subjective opinions or incomplete understanding of the trainer.

A corpus-based approach to translation evaluation has the following characteristics. Firstly, it is based on the analysis of a comparatively large and carefully selected collection of naturally occurring texts that are stored in machine-readable form (i.e., a corpus). Secondly, because it analyzes actual patterns of language use in the corpus, it is empirical and therefore objective. Thirdly, the corpus-based approach takes advantage of computational tools and methods for manipulating the corpus, arranging the data in ways that make it possible to spot items and patterns that would be difficult to identify in other types of resources. An additional advantage of computers is that they provide consistent and reliable analyses (i.e., they do not change their minds or get distracted). Finally, the corpus-based approach combines both quantitative and qualitative techniques; a computer is capable of churning out counts of linguistic features, but the translator trainer is responsible for exploring and interpreting these and other data in order to learn about patterns of language use.

It is my contention that translation evaluation will benefit from the adoption of a corpus-based approach. Given that translation evaluation entails making judgements about appropriate language use, it should not rely on intuition, anecdotal evidence or small samples; rather, such studies require empirical analyses of larger bodies of authentic text, as found in the corpus-based approach. Nevertheless, the corpus-based approach can be seen as complementary to some elements of more traditional approaches; for example, information provided by subject field experts can be explored more fully in a corpus, intuition can be verified using a corpus, or terms found in dictionaries or parallel texts can be used as access points into a corpus.

Translation evaluation can take place in many different contexts, but this article focuses on the development of an approach to translation evaluation that can be applied in the context of translator training. In brief, it shows how corpora can be used to help translator trainers who are not subject field experts to identify the conceptual and linguistic information that they need in order to be able to evaluate student translations. As such, it outlines a number of guidelines for helping evaluators to compile and exploit suitable Evaluation Corpora. However, it does not attempt to identify a comprehensive typology of translation errors, nor does it provide specific indications as to how translations should be graded (i.e., there are no discussions along the lines of 'errors of type A should result in the deduction of X number of marks'). Although it is clearly the case that translator trainers will have to grade at least some of their students' translations, the scope of this article is to develop a more general methodology that translator trainers can adopt in order to equip themselves with the information they need in order to be able to make sound decisions with regard to the seriousness of the errors they encounter.

The article is divided into four main sections. Section 1 briefly outlines some of the challenges facing translator trainers who need to evaluate student translations in an academic context. Section 2 provides a brief introduction to corpora and corpus analysis tools. Section 3 describes the general design of an Evaluation Corpus. Section 4 provides an example of how an Evaluation Corpus can be constructed and 
used to help a translator trainer evaluate student translations of a short text on digital versatile discs (DVDs).

\section{Challenges Facing Evaluators in an Academic Context}

Translation evaluation is of central interest in the context of translator training, and yet, as observed by Hatim and Mason (1997: 197), it is an area that is underresearched and under-discussed. One reason for this relative neglect is summarized by Larose (1998: 163), who notes that the problems associated with the evaluation of translated texts are of cosmic proportions. The main difficulty surrounding translation evaluation is its subjective nature: the notion of quality has very fuzzy and shifting boundaries, so that a translation which is deemed appropriate in one context or by one evaluator may be deemed unacceptable in other circumstances. As many translation researchers and practitioners have pointed out, the same set of criteria cannot be applied uniformly to all translation activity (e.g. Hönig 1998: 14; Larose 1998: 164).

Translator trainers, who must evaluate translations in an academic context, are faced with additional challenges. In a professional setting, clients who commission translations are not interested in educating the translator-if the quality of the target text proves to be unacceptable, the commissioners will simply take their business elsewhere. In contrast, a translator trainer has an obligation to help students improve their performance, and this includes providing not only a grade, but more importantly, providing constructive feedback with regard to translation errors or difficulties (Hönig 1998: 32). To do this, many translator trainers end up relying on personal experience, but this can be problematic. In an ideal world, translator trainers would be equipped with the vast array of knowledge and experience required to allow them to fairly and objectively evaluate their students' translations; however, in the real world, even highly experienced translators and trainers regularly find themselves thrown into unfamiliar territory because relatively few of them have the luxury of working only in a narrow field of specialization. For example, McMillan (1987: 89) describes the situation of translators working for the World Bank, who are called upon to handle an immense range of texts, such as reports on town planning in Brazil or on cardboard manufacturing in Yugoslavia, research papers on East African narcotics, detailed descriptions of contraceptive methods and practices as part of an in-depth study of the effects of the population explosion on development, etc. Therefore, in order to properly prepare students for entering the translation profession, Fraser (1996: 246) advocates that students need to be exposed to as wide a range as possible of translation material and text-types. While this is sound advice, it is nevertheless unreasonable to expect a translator trainer to be an expert in all the subjects that could come up. Naturally, this makes the evaluation of student translations challenging to say the least. Translator trainers therefore require some type of resource that can be used to help them evaluate and provide accurate and objective feedback on student translations in highly specialized subject fields, particularly if they themselves are not trained experts in these fields. It is my contention that a specially designed Evaluation Corpus can help to meet this need. 


\section{Corpora and Corpus Analysis Tools}

An electronic corpus is generally understood to be a large collection of machinereadable texts that have been gathered according to specific criteria. In a translation context, a suitable corpus might be one containing texts that correspond to the intended skopos of the target text (e.g. texts of a specific text type that were published within a certain time frame and that treat a given topic). In this way, a corpus is similar to the conventional printed parallel texts ${ }^{1}$ used by many translators (e.g. Schäffner 1998; Williams 1996); however, an electronic corpus is generally much larger than a printed corpus and it can be processed with the help of computerized tools known as corpus analysis tools. ${ }^{2}$ Such tools let users manipulate and display the information contained within a corpus in a variety of useful ways. Most corpus analysis tools contain at least the following two main features: word frequency lists and concordancers.

A word frequency list allows users to discover how many different words are in the corpus and how often each appears. These two figures are referred to as types and tokens. Take for example the sentence "I really like translation because I think that translation is really, really interesting." This sentence contains a total of thirteen words; therefore, we could say that it contains thirteen tokens. However, some of the words appear more than once in the sentence (i.e., 'I', 'really', 'translation'); therefore, the sentence contains only nine different words, and these are known as types. In a word frequency list, the types are presented in a list and the number of tokens (i.e., the number of times that word occurs) is shown beside the type, as illustrated in table 1 . Word frequency lists can also be manipulated in a number of ways. They can be sorted in alphabetical order or in order of ascending or descending frequency. Words belonging to the same lemma (i.e., words which have the same stem and belong to the same major word class, differing only by spelling or inflection) can be counted together or separately, as can words beginning with upper or lower case letters. Stop lists, which are lists of words to be ignored, can also be used. This could be done, for example, in order to eliminate common function words such as prepositions or conjunctions.

Frequency information can be useful for helping translators decide which term to use when faced with a number of potential synonyms or translation equivalents. For instance, this type of data can help them to determine whether a given term is commonly used by experts in the field, or whether it is simply one author's idiosyncratic preference.

TABLE 1

An extract from a word frequency list showing types and tokens sorted by frequency.

\begin{tabular}{|ll|ll|ll|ll|}
\hline DVD & 765 & video & 126 & not & 89 & player & 80 \\
is & 341 & we & 121 & said & 85 & all & 79 \\
will & 208 & have & 116 & consumer & 83 & technology & 75 \\
it & 177 & market & 100 & PC & 82 & computer & 73 \\
drive & 154 & digital & 97 & MPEG & 81 & chip & 71 \\
\hline
\end{tabular}


A concordancer retrieves all the occurrences of a particular search pattern in its immediate contexts and displays these in an easy-to-read format. The most commonly used format is known as a KWIC (key word in context) display which shows one occurrence of the search pattern per line with the search pattern itself highlighted in the centre of the screen as shown in table 2. The extent of the context on either side of the search pattern is variable. Moreover, these contexts can be sorted in a variety of ways, such as in order of appearance in the corpus, or alphabetically according to the words preceding or following the search pattern. Concordancers have also become quite flexible, allowing functions such as case-sensitive vs non-case sensitive searches, wildcard searches (e.g. 'play*' to retrieve 'play', 'played', 'player', 'players', 'playing', 'plays', etc.), and searches where another term must appear within a user-specified distance of the search term (e.g. contexts where 'play' appears within five words of 'DVD').

TABLE 2

An extract from a KWIC display of the results of a query on the term 'player'.

\begin{tabular}{|rll|}
\hline atsushita's slick, portable DVD & player & with a color LCD and To \\
ndows Explorer, but their movie & player & software refused to pla \\
ndows NT compatibility. The DVD & player & software in all these k \\
ers with a "record" button. The & player & will not even have the \\
o three years," he says. Such a & player & would have a display ab \\
t's eye, Wood said. A Super VCD & player & is believed to improve \\
\hline
\end{tabular}

In translation, the main advantage afforded by concordancing tools is that they allow translators to see terms in a variety of contexts simultaneously, which in turn allows them to detect various kinds of linguistic and conceptual patterns that are sometimes difficult to spot in isolated printed resources (e.g. meanings of terms, related terms, typical phrasal patterns).

The majority of corpus analysis tools also offer a number of other features, which often combine the data produced by the concordancer and word frequency counts. For example, statistics regarding the collocation patterns of words (i.e., patterns of words that 'go together') can be generated. This type of information can be useful for identifying typical usage patterns.

\section{Designing an Evaluation Corpus}

It was established in section 2 that a corpus is not a random collection of texts but rather a collection of texts that have been selected according to specific criteria in order to meet the needs of the project at hand. Clearly, the value of what comes out of a corpus is largely dependent on what texts are included in it. Criteria for designing general language corpora have been reasonably well-documented in the literature (e.g. Engwall 1994); however, these criteria cannot be adopted wholesale for the design of a special-purpose corpus such as an Evaluation Corpus. Rather, special care must be taken to ensure that the contents of the corpus will meet the specific needs of the intended users. In this case, the intended users are translator trainers who are faced with the task of evaluating a relatively short specialized translation (up to several thousand words) in a subject field that is relatively unfamiliar to them-a scenario that is typical of many translator training programmes. ${ }^{3}$ 
The Evaluation Corpus is the collective name given to the collection of texts that is divided into four main subcorpora: the Comparable Source Corpus, the Quality Corpus, the Quantity Corpus and the Inappropriate Corpus. These subcorpora differ with regard to their content and intended function. The following sections outline and explain some of the general design principles to be considered when compiling an Evaluation Corpus. These principles will later be exemplified in section 4 with reference to the construction of an Evaluation Corpus on DVDs and its application for evaluating some student translations.

\subsection{Comparable Source Corpus}

The first subcorpus contained in the Evaluation Corpus is referred to as the Comparable Source Corpus and it is actually an optional component. The decision about whether or not to include a Comparable Source Corpus in an Evaluation Corpus may depend on factors such as time, text type and the skopos of the target text. ${ }^{4}$

The essential idea behind a Comparable Source Corpus is that it contains a selection of source language texts that are similar to the source text in terms of text type, publication date and subject matter. The purpose of the Comparable Source Corpus is to allow the evaluator to gauge the "normality" of the source text with regard to other source language texts of that type.

Baker (1997: 183) describes 'normalization' as a feature of translated texts, noting that normalized texts display exaggerated features of the target language and conform to its typical patterns. Meanwhile Kenny (1998: 515) defines 'sanitization' as the suspected adaptation of a source text reality to make it more palatable for target audiences. Both normalization and sanitization result in deliberately chosen unconventional lexical or syntactic source text features being watered down in translation so that the target text fits in with the conventions of the target language. What was creative and original in the source text becomes humdrum and typical in the target text.

If the source and target texts both have the same skopos, then it may prove useful to have a Comparable Source Corpus to establish whether or not a passage in the source text is creative. It is important for evaluators to establish what the conventions of source language use are for a particular text type so that they can determine whether the author of the source text in question has followed these conventions or whether he or she has taken a deliberately different or more creative approach to language use. In order to determine whether or not a target text has been inappropriately normalized or sanitized, evaluators can first use the Comparable Source Corpus as a reference corpus to establish the relative normality of the source text. As a second step, they can then use the Quantity Corpus (see section 3.3) as a reference corpus to establish the relative normality of the target text. The source and target texts are intended to have the same skopos, and they should have a similar degree of normality with respect to their relative reference corpora. In other words, if the source text is deemed to be normal (in terms of vocabulary, register, style, etc.) with reference to texts in the Comparable Source Corpus, then the target text should also appear normal when compared with texts in the Quantity Corpus. However, if the source text is deemed to be 'abnormal' (e.g. more creative, different register, etc.) when compared with the Comparable Source Corpus, then the target text should 
display the same types of "abnormalities" when compared with texts in the Quantity Corpus.

\subsection{Quality Corpus}

The Quality Corpus is a high-quality subcorpus consisting of texts that have been hand-picked primarily for their conceptual content. It is very small by corpus linguistics standards ${ }^{5}$, containing only four or five texts with a total word count in the area of 5, 000 words. The texts in the Quality Corpus serve much the same purpose as conventional parallel texts in translation (see section 2); therefore, they should be authentic texts written by subject field experts that provide a good explanation of the subject matter covered in the source text to be translated. Because the Quality Corpus is used primarily as a source of conceptual, rather than linguistic, information, it is not necessary for all these texts to be of the same text type as the source text. It is, however, important that they are complete texts rather than extracts or samples as favoured by some types of general language corpora, such as the Longman/Lancaster English Language Corpus (Summers 1993). If a text were to be randomly chopped, it could result in an important conceptual explanation being omitted or cut short.

If necessary, some of these texts in the Quality Corpus can treat the subject matter in a broader fashion than does the actual source text in question. This may be useful for evaluators who have an extremely limited knowledge of the field and are looking for a gentle introduction that will enable them to situate the specific subject within the broader subject field. Evaluators who already have some knowledge of the subject may prefer to focus on texts that deal more specifically with the precise topic of the source text.

It is also worth pointing out that slightly older texts often have an intrinsic knowledge. In our experience, experts writing on a particular topic tend to provide clearer and more detailed explanations of relevant concepts when an idea, product, technology, etc. is first introduced or begins gaining popularity. As time goes by, these concepts become part of the general knowledge of subject field experts and hence the concepts, acronyms, etc., are not explained as frequently or in as much detail. Nevertheless, if the subject in question is part of a field that is evolving quickly, there is a significant risk associated with consulting only older documentation: as ideas evolve, the concepts, as well as the terms used to describe them, may evolve also. Therefore, at least some of the texts contained in the Quality Corpus should be current.

Because the Quality Corpus is small in size and has been hand-picked for relevance, translator trainers can initially (skim) read all the contents of this corpus, treating it in much the same way as they would conventional parallel texts. Perusing the Quality Corpus will help the translator trainer to become familiar with the basic concepts in the subject field and to identify some of the key terms. This initial reading can later be followed by a more focused computer-assisted analysis. Clearly this will not transform the translator trainer into an immediate bona fide subject field expert, but if the texts are well chosen, they can serve as a benchmark against which the translator trainer can judge whether or not students have correctly understood the concepts and ideas expressed in the source text. 


\subsection{Quantity Corpus}

When using conventional resources, such as parallel texts, most evaluators stop after gathering a selection of documents that resemble the Quality Corpus as described above. However, there are a number of reasons why it is not appropriate to rely exclusively on the Quality Corpus to evaluate a translation. Firstly, because it is a relatively small collection, there is no real way of knowing whether the texts that have been selected are truly representative of the text type at large, or whether the authors who wrote those texts have used generally accepted terminology, phraseology, etc. Secondly, as mentioned in section 3.2, the texts contained in the Quality Corpus may often be somewhat "older" texts as these have an intrinsic knowledge value; however, it is commonly accepted that terms go through life cycles and therefore, a term which was appropriate in the past may no longer be so.

The Quantity Corpus is therefore designed to provide a larger and more representative sample of the specialized language in question. Unfortunately, the question of how large and how representative is not entirely straightforward. External factors such as time and availability of data will have an influence on this, but what should evaluators aim for under ideal circumstances? It is true that in corpus linguistics, bigger is not necessarily better-a small but well designed corpus may provide more useful data than a corpus that is larger but less well thought out. Nevertheless, a corpus consisting of only a few short texts will not likely provide enough instances of any given search term to allow users to identify patterns. In my experience, I have found that Quantity Corpora ranging in size from 20,000 to 200,000 words have proved useful. Corpora larger than this take too long to compile, while smaller corpora do not contain enough data to be interesting. Obviously, the corpora that contain 200,000 words tend to provide a better range of data, especially for subject fields that are not extremely narrow; however, such corpora typically take longer to put together. It is worth constructing this size of corpus if it is likely to be used over a longer period of time (e.g. over an entire semester). Corpora in the 20,000 word range have still proved to be worthwhile, particularly in highly specialized subject fields where the language is very restricted and where large quantities of data may not be easily available. In addition, if the corpus is not likely to be used more than once or twice, it is not worth investing a great deal of time compiling it. Although the size of even a large Quantity Corpus may seem small in comparison to many general language corpora, which often run to many millions of words, it is commonly accepted that corpora intended for specialized applications can be smaller than those used for general language research (Engwall 1994: 51).

The texts contained in the Quantity Corpus should be relatively recent, but exactly how recent will depend on the subject field. In subject fields that are evolving quickly, texts should not be more than two or three years old, but in fields that are more stable, texts that are five or six years old may still prove valuable. Where possible, the number of texts dating from each time period (e.g. each calendar year) should be roughly comparable to enable translators or evaluators to track terminological changes over time. For this reason, it may prove useful to divide the Quantity Corpus into further subcorpora-one for each year. A corpus analysis tool such as WordSmith (see section 2) allows users to consult multiple corpora at once, so all the subcorpora can be consulted together to get an overall picture, or each subcorpus 
can be consulted individually to check for the currency of a particular term during a particular time frame.

The Quantity Corpus is compiled in a more semi-automated fashion ${ }^{6}$ than the Quality Corpus and once compiled, it can be used to allow the translator trainer to verify the appropriateness of the terminological, phraseological and stylistic choices made by students. The volume of data makes it possible to spot patterns more easily, to make generalizations, and to provide concrete evidence to support decisions; however, one disadvantage to interacting solely with a large electronic corpus is that it is easy to lose sight of the fact that translation is a text-based activity. When conducting corpus analysis, the focus tends to be on micro-contexts (e.g. the KWIC displays described in section 2). Of course, most corpus analysis software gives users the option of expanding the context to several lines or even of looking at the complete text, but the primary power of corpus analysis remains at a sub-text level. If a user simply wanted to read entire texts, there would be no advantage to collecting them in electronic form. For this reason, evaluators may decide that other resources (e.g. printed parallel texts) may be more useful than corpora for evaluating certain elements of translation. Another drawback may be that the texts sought for inclusion in the corpus may not be readily available in electronic form (e.g. owing to the subject matter, language or text type in question). At this point, it may be useful to remind readers that no resource is perfect and comprehensive, including an Evaluation Corpus. The purpose of this article is not to promote corpora as being a panacea that will solve all problems but rather to alert readers to the fact that corpora do have a number of strengths that can complement other types of resources.

In combination with a corpus analysis tool, the Quantity Corpus can be used to investigate the appropriateness of specific terms or expressions proposed by the students, to check for preferred spellings, to identify appropriate collocations, to verify semantic prosody, to investigate the appropriateness of the register, style, etc. The evidence found in the corpus can then be presented to the student. In my experience, I have found that when students are presented with this type of concrete, corpus-based evidence (whether positive or negative), they are less likely to feel that a subjective decision has been made, and they are more likely to accept and learn from the correction.

\subsection{Inappropriate Corpus}

The final subcorpus contained in the Evaluation Corpus is known as the Inappropriate Corpus, and as the name suggests, it is a corpus containing "inappropriate" parallel texts. A translator trainer is responsible not only for assigning a grade to a student's translation, but also for providing constructive feedback. Part of the trainer's job is to try to determine why a student has made an error (Kussmaul 1995: 130) so that feedback can be presented which will help that student to avoid making similar errors in the future.

As pointed out by Pearson (2000: 237), translation students frequently show poor judgement when sourcing terminology and phraseology from parallel texts. For example, they are often primarily concerned with identifying parallel texts that deal with the subject matter in question, but they do not ensure that the texts they choose are parallel to the source text with respect to its other features, such as register, technicality 
and text type. In addition, in my experience, I have found that sometimes students can also make poor choices with regard to the actual subject matter of the text, selecting texts that may belong to the same broad subject field, but to a different (though possibly related) subfield.

The size of the Inappropriate Corpus will vary depending on the subject matter of the translation. Some subjects may be treated in only a limited number of different text types, some subjects may be very recent, and some may have no closely related subfields. In such cases, the Inappropriate Corpus would be relatively small. Other subjects may be more well established and of wider interest, in which case, the Inappropriate Corpus would be larger.

The purpose of the Inappropriate Corpus is to help the translator trainer uncover the mysteries of where students come up with some of the unsuitable equivalents that they propose. Therefore, the texts contained in the Inappropriate Corpus are texts which, on the one hand, may deal with the subject matter in question, but which differ significantly from the source text in terms of criteria such as text type or publication date, or on the other hand, texts which treat other subfields of the broad subject field.

If a student has used a term or phrase which does not appear in either the Quality Corpus or the Quantity Corpus, the evaluator can then check to see if it appears in the Inappropriate Corpus. If it does appear in the Inappropriate Corpus, the evaluator can look to see what kind of text it appeared in and thereby possibly determine why it was an unsuitable choice (e.g. the term is outdated, the register is not appropriate for the text type, etc.). In this way, the evaluator can once again provide the student with concrete evidence rather than merely putting a line through the error.

\section{Using an Evaluation Corpus to Assess Student Translations}

Now that the general design principles have been outlined, these will be exemplified by describing the design, compilation an application of an Evaluation Corpus. For the sake of clarity, I will describe a scenario where the target text has the same communicative function as the source text; in other words, both the source and target text can be said to have the same skopos ${ }^{7}$. For this example, I will describe the compilation of an Evaluation Corpus in the subject field of digital versatile discs (DVDs) which was used to help evaluate translations of an article entitled "Le DVD tient ses promesses" which appeared in the February 1999 issue of a French popularized science magazine called Sciences et Avenir. The students were asked to translate the text as if for publication in a current issue of New Scientist, a general science magazine that addresses a lay audience interested in science and technology. A copy of the source text is provided in the appendix.

It should be mentioned that the following sections simply contain a number of examples of how a corpus can be used to help translator trainers evaluate student translations. These examples should not be viewed as a recipe that can be followed in a step-by-step fashion, nor as a comprehensive set of techniques for compiling and extracting information from a corpus. Each text, each language pair and each subject field are different, and what this article provides is a starting point and a number of suggestions that translator trainers can adapt and develop to meet their own needs. 


\subsection{Contents and Application of DVD Comparable Source Corpus}

Because the skopos of both the source and target texts are the same, because the text type is a popularized scientific text that is addressed to a lay audience, and because there is a lot of hype surrounding the subject of DVDs, I felt it would be worthwhile to begin by compiling a Comparable Source Corpus to investigate possible lexical creativity which may be at risk for normalization or sanitization in the target text.

The DVD Comparable Source Corpus consists of nine texts (4, 043 words) taken from a variety of French-language popularized science magazines including Science et Vie, Québec Science, La Recherche and Sciences et Avenir dating from 1998 and 1999.

This corpus was used to investigate, for example, the passage "Il [DVD] va envoyer au tapis CD-Rom, CD-Audio et VHS." The expression envoyer au tapis is quite a strong and vivid one with a considerable physical association (as in knocking someone out in a boxing match). The Comparable Source Corpus revealed the following expressions used to describe the relationship between DVD and other media: remplacer (6), être le successeur (3), supplanter (1), éradiquer (1). Compared with the majority of these examples, the expression envoyer au tapis packs a lot of punch! Remplacer ('replace') and etre le successeur ('to succeed' or 'to be the successor of') are quite mild, and although supplanter ('to supplant') and particularly éradiquer ('to eradicate') are more forceful, they are still not as vivid as envoyer au tapis. Therefore, it would seem that the author really believes in the future of DVD and wants to make a bold statement to that effect.

In the student translations, a number of students translated envoyer au tapis by 'replace' and some others selected 'overtake'. These translations are examples of normalization - the author's creativity has been neutralized. The basic semantic meaning has been captured, but the translation lacks the flair and zeal of the original. An examination of the Quantity Corpus (see section 4.3) reveals that four texts do indeed use relatively straightforward terms such as 'replace' or 'outsell' to describe the relationship between DVD and CDs, but other texts contain much more interesting and forceful descriptions, including 'attack', 'challenge, 'invade', 'make obsolete, 'push aside', 'put the squeeze on' and 'sound a death knell for'. Placed alongside these texts, a translation such as 'replace' would cause this passage, which in the source text stood out as being forceful and vibrant, to pale into insignificance. These concrete examples can be used to demonstrate to students that un-normalized translations are possible, and in this case preferable, given the skopos of the target text.

\subsection{Contents and Application of DVD Quality Corpus}

The DVD Quality Corpus consists of five texts totalling 3, 931 words. These texts were all taken from popularized science or computing magazines and they were hand-picked because they offer clear explanations of the subject matter.

- "Much Ado about DVD” New Scientist (August 1996)

- "How DVD Works" Windows Magazine (October 1997)

- "Hot or Hype?-New and emerging technologies" Windows Magazine (January 1998)

- "The DVD Invasion" Computer News (June 1998)

- "DVD put to the test" EE Times (Dec 1999) 
Several of the texts are somewhat older than the source text (one by almost three years). As noted in section 3.2, older texts have an intrinsic knowledge value because concepts are explained more clearly and in more detail when technologies or products are first introduced. Nevertheless, because the field is evolving quickly and the terms and concepts may have evolved as well, I was certain to include some more recent publications also.

This corpus was useful for learning some of the basic concepts and terms associated with the subject field. It provided information that made it possible to constructively correct some student translation errors such as the following. Note that while a given evaluator may not need recourse to a corpus to make some of these corrections, it is nonetheless useful to be able to provide the student with concrete corpus-based feedback. In my experience, this type of concrete feedback is much appreciated by students.

Source Text: Comme le CD audio, le DVD est lu par un faisceau laser qui balaie les pistes du disque percées d'une infinité de trous, porteurs de l'information binaire. La différence entre DVD et CD réside dans la taille des trous: $0,83 \mu \mathrm{m}$ pour le $\mathrm{CD}, 0,40 \mu \mathrm{m}$ pour le DVD, et la distance entre les pistes (respectivement 1,60 $\mu \mathrm{m}$ et $0,74 \mu \mathrm{m}$ ).

Student Translation: Like the audio CD, the DVD is read by a bundle of lasers which brush the pits of the disk etched with an infinite number of gaps which carry binary information. The difference between DVD and CD lies both in the size of the gaps$0.83 \mu \mathrm{m}$ for the CD and $0.40 \mu \mathrm{m}$ for the DVD, and in the distance between the pits $(1.60 \mu \mathrm{m}$ and $0.74 \mu \mathrm{m}$ respectively).

The first conceptual misunderstanding is the translation of faisceau by 'bundle of lasers' rather than by 'laser beam'. The student has probably consulted a bilingual dictionary that provided 'bundle' as one possible translation of faisceau, but it is not the correct one in this context. A quick check in the corpus reveals that while bundle appears four times, it is only in reference to 'bundled software'-free programs that are given to people when they purchase a DVD player. In addition, there are no instances of 'laser' being used in the plural, but there are several of 'laser beam' and many more of simply 'laser' preceded by a definite or indefinite article.

The next main conceptual misunderstanding is the translation of balaie by 'brush.' 'Brush' implies a sort of physical contact which simply does not occur in this situation. A corpus searching using the pattern 'brush ${ }^{\star}$ ' reveals that there are no instances of lasers brushing discs. It appears that the student has once again consulted a bilingual dictionary and selected quite a literal translation-one that is not appropriate to the context. A better choice from the dictionary might have been 'sweep' as in many instances, light can be referred to as sweeping, however, the corpus reveals that even 'sweep"' does not typically feature in this specialized language. As illustrated in table 3, the concordances for 'laser' clearly show that in the context of DVDs, lasers are used to 'read' information.

TABLE 3

Concordances retrieved from the DVD Quality Corpus illustrating that a 'laser' is used to 'read' the information contained on DVDs.

create a pattern that the laser can o has also added a laser modified to laser to focus deep into the disc to read. With current disc coatings,

read DVD as well as CD-R and CD-RW

read a second data layer. Double-s 
The next two conceptual errors-the translation of pistes by 'pits' and of trous by 'gaps'-are related. 'Pits' is in fact a technical term belonging to the specialized language used to discuss DVDs; however, it is the correct translation of trous rather than of pistes. Having already used 'pits' to translate pistes (perhaps because of the superficial similarity of the two words?), the student was then forced to find a different translation for trous and ended up by choosing the unsatisfactory term 'gaps'. As shown in table 4, a concordance search on 'pits' reveals two contexts that clearly indicate the relationship between 'pits' and 'tracks'. The fact that the second context gives specific dimensions for both 'pits' and 'tracks' means that interlingual equivalences can be unequivocally established with the source text terms.

TABLE 4

Two contexts retrieved from the DVD Quality Corpus that illustrate the relationship between 'pits' and 'tracks'.

The fact that the pits are smaller means they can be packed more tightly into the tracks.

The use of smaller pits ( 0.4 microns for the DVD vs. 8.3 microns for the $C D)$ and narrower track-to-track spacing ( 0.74 microns for the DVD vs. 1.6 microns for the $\mathrm{CD}$ ) means that there's room on the DVD for nearly four times as much information per layer than on a CD.

\subsection{Contents and Application of DVD Quantity Corpus}

The DVD Quantity Corpus was compiled in a much more semi-automated fashion than was the hand-picked Quality Corpus. Texts were extracted from CD-ROMs (e.g. New Scientist, Computer Select) and web sites (e.g. TechWeb) using a combination of user-defined selection features including keywords (DVD), publication date (1997-1999) and text type (articles). The texts retrieved had a total word count of 27,446 and the compilation process took approximately 25 minutes. Because the corpus was fairly small and covered a restricted time period, the decision was made not to further subdivide the Quantity Corpus according to year.

Some of the types of linguistic and stylistic choices made by the students that can be investigated with the help of the Quantity Corpus are outlined below, and they range from straightforward verification exercises to more sophisticated investigations.

With regard to verification, an evaluator may simply wish to confirm that a student has made a suitable choice with regard to a particular term or phrase. For example, one student has rendered the term le CD audio by 'the audio CD'. An evaluator may feel instinctively that this is the right choice, but may wish to confirm his or her intuition by investigating this term in the Quantity Corpus to ensure that the term is not in fact 'CD-audio' (in parallel with the form 'CD-ROM', for example). A search on the term 'CD' reveals 219 occurrences, but by sorting these terms (first to the left and then to the right), it can be quickly established that while both 'audio CD' and 'CD-audio' seem to be acceptable terms, 'audio CD' seems to be the preferred term with 6 occurrences in the corpus whereas ' $\mathrm{CD}$-audio' appears only once.

Another use for the corpus is demonstrating that although the preferred spelling of CD-Rom and DVD-Rom in French entails using lower case 'om', the overwhelming preference in English is to use all upper case letters: CD-Rom (1 occurrence), CDROM (102 occurrences), DVD-Rom (0 occurrences), DVD-ROM (107 occurrences).

In addition, whereas one student used CD-ROM as if it were invariant in num- 
ber ('it combines the storage equivalent of five to seven CD-ROM'), the corpus shows that while ROM alone is invariant in number, CD-ROM is actually pluralized by adding an 's' to create CD-ROMs.

In another example, a student has rendered the unit of measure Go (as in permettant au DVD de stocker 4,7 Go sur une face et jusqu' à 17 Go sur des modèles à venir double face et double couche!) from the source text as 'gigaoctet' in the target text. A corpus search turns up no occurrences of 'gigaoctet' (or indeed of '* octet'). The fact that there were no occurrences alerts the evaluator to the fact that more research is required in order to establish the equivalent, and number of strategies are possible. As demonstrated in table 5, a context search on 'giga ${ }^{\star}$ ' or indeed even on ' $\mathrm{G}^{\star}$ ' within a five-word span of 'stor' turns up a selection of useful concordances, as do searches on '4.7' and on ' 17 '.

TABLE 5

A context search in which ' $G$ ' appears within a five-word span of 'stor'.

OMs; specifically, they give you 2.1 her much more tightly:as much as 4.7 n't be overly impressed with the 4.7 ntains 26 times the storage space- 17 , dual-layer discs can hold about 17 mputer-related products that promise
GB of storage. But their performan Gbytes of data can be stored on on Gbytes of data stored on DVD-ROM p Gbytes compared with CD's 650 Mbyt Gbytes. DVD's increased storage ca Gigabytes of optical storage. But

An interesting choice made by one student was the decision to render the title of the source text, Le DVD tient ses promesses, by 'DVD's keeping her promises'. Although the French pronoun ses can indeed be translated by 'his', 'her' or 'its', the normal choice when referring to inanimate objects is 'its'. Nevertheless, there are exceptions, such as the convention of using feminine pronouns when referring to ships. As shown in table 6, the corpus can be used to quickly demonstrate that DVD is not among these exceptions and that the impersonal possessive pronoun 'its' is the appropriate choice here.

TABLE 6

Concordance lines revealing that 'DVD' is associated with the impersonal possessive pronoun 'its'.

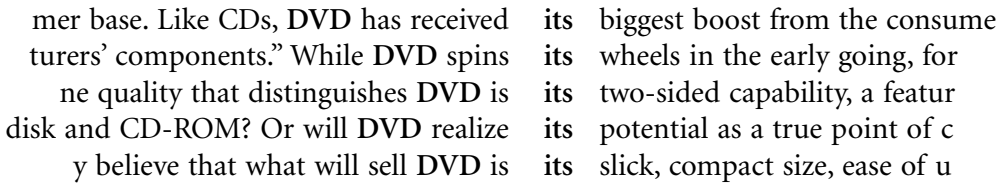

Other problem terms in student translations included pistes and trous. These terms were previously discussed in the context of conceptual misunderstandings, but there were other cases where students who appeared to understand the concepts still made poor terminological choices. For instance, a number of students elected to translate pistes by 'grooves', while trous was translated by 'holes'. There were no occurrences of 'grooves' in the corpus, and the sole reference to 'hole' was referring to the large hole in the centre of a CD. In the case of these examples, one way of using the corpus to identify possible equivalents could be to use the measurements (i.e., 
$0.83 \mu \mathrm{m}, 0.4 \mu \mathrm{m}, 1.6 \mu \mathrm{m}$ and $0.74 \mu \mathrm{m}$ ), which turn up contexts containing references to 'tracks' and 'pits'.

Identifying appropriate collocations within the specialized language of DVDs also posed difficulties for some students. The example that 'lasers read' information was discussed in the section on conceptual misunderstandings, but another example is the choice of the translation 'riddled with pits' as an equivalent for percées d'une infinité de trous. This translation is problematic in a number of senses. Firstly, the collocation 'riddled with pits' sounds a bit peculiar, and the corpus supports this intuition by revealing that there are no instances of 'riddled' collocating with 'pits' (in fact, 'riddl ${ }^{*}$ ' does not appear in the corpus at all). Although 'riddled with' can indeed have the semantic meaning roughly equivalent to 'containing much $\mathrm{X}$ or many $\mathrm{Xs}$ ', one reason that 'riddled' sounds strange here is that it has an overwhelmingly negative semantic prosody. An evaluator can demonstrate this negative prosody to the student by consulting another type of corpus, such as the existing British National Corpus $(\mathrm{BNC})^{8}$, which is a large general language corpus containing 100-million words of contemporary British English. Table 7 contains twenty concordances that have been randomly selected from the 177 occurrences of this term in the BNC.

TABLE 7

Twenty concordances for the term 'riddled' that have been randomly selected from the 177 occurrences of this term in the British National Corpus.

\begin{tabular}{|c|c|c|}
\hline $\begin{array}{r}\text { Her body was } \\
\text { t lavas is that they are often } \\
\text { here of this little community, } \\
\text { is brown flawless skin, he was } \\
\text { has, from its inception, been } \\
\text { ar-old teaboy Abdul Khalid was } \\
\text { llow in the corner of a field, } \\
\text { His body was } \\
\text { d false confessions, scribbles } \\
\text { a child, were killed when men } \\
\text { His plane was } \\
\text { 'death of hope' in a precinct } \\
\text { British society is } \\
\text { Wounded, and with his aircraft } \\
\text { ocent-looking sarnies could be } \\
\text { cheated death when his car was } \\
\text { sion, replete with expediency, } \\
\text { said no need to worry, angel, } \\
\text { ul child but I would have been } \\
\text { does not mean that the City is }\end{array}$ & $\begin{array}{l}\text { riddled } \\
\text { riddled } \\
\text { riddled } \\
\text { riddled } \\
\text { riddled } \\
\text { riddled } \\
\text { riddled } \\
\text { riddled } \\
\text { riddled } \\
\text { riddled } \\
\text { riddled } \\
\text { riddled } \\
\text { riddled } \\
\text { riddled } \\
\text { riddled } \\
\text { riddled } \\
\text { riddled } \\
\text { riddled } \\
\text { riddled } \\
\text { riddled }\end{array}$ & $\begin{array}{l}\text { with arthritis. } \\
\text { with holes. } \\
\text { with prejudice and of limited in } \\
\text { with disease-disease he had c } \\
\text { with racist practices. } \\
\text { with bullets as he sat in his ca } \\
\text { with holes and scattered with fr } \\
\text { with bullets from the Skorpion. } \\
\text { with hatred or guilt, the anonym } \\
\text { a bus with gunfire in the indep } \\
\text { with bullets, and one cut an art } \\
\text { with drugs. } \\
\text { with miscarriages of justice. } \\
\text { with cannon and machine gun fire } \\
\text { with bacteria, such as listeria, } \\
\text { by sniper fire. } \\
\text { with past prejudices, they can o } \\
\text { with diseases I'm sure, apart fr } \\
\text { with doubt for most of its life. } \\
\text { with fraud or that the regulator }\end{array}$ \\
\hline
\end{tabular}

It is clear from looking at these examples that 'riddled' is overwhelmingly associated with negative things, such as bullets and gunfire, criminal activity (e.g. fraud, drugs), disease and other generally unpleasant things (e.g. racism, prejudice, hatred, guilt, doubt, etc.). As pointed out by Louw (1993), once a word becomes imbued with an unfavourable prosody, it cannot, in normal circumstances, be used in a neutral or favourable environment (except for ironic effect). The discussion about the pits on a DVD is a neutral environment, but the use of 'riddled' involves the intro- 
duction of its associated negative prosody and this consequently makes the whole phrase seem peculiar.

Another problem with using the term 'riddled' is that it also contains the notion of randomness. Holes created by gunfire and bullets are not typically laid out in an orderly fashion. In contrast, the contexts from the corpus indicate that the size and placement of the pits on a DVD are measured precisely in microns.

With regard to style, the point has already been made that one of the drawbacks of corpus analysis is that it tends to focus on lexis and on small sections of text. Therefore, a corpus-based approach may not be the most useful way of evaluating the stylistic features of a translation. Nevertheless, corpus analysis software such as WordSmith Tools can be used to make crude comparisons such as the average sentence length of texts in the corpus as compared to the average sentence length in a student translation (provided, of course, that the target text has been submitted in electronic form). Searches on words such as 'by' might also be useful for getting a general idea as to whether or not passive structures are common in a given text type, searches on ' $t$ ' or 'll' can give an indication as to whether or not contractions feature heavily, and searches on 'you' can reveal whether or not it is appropriate to address the reader directly. One stylistic feature that was revealed using the DVD Quantity Corpus is that the symbol ' $\mu \mathrm{m}$ ' is not used in popularized texts in English; rather, it is more stylistically appropriate to write out the term 'microns'.

\subsection{Contents and Application of DVD Inappropriate Corpus}

The final element of the DVD Evaluation Corpus is the Inappropriate Corpus. The purpose of the Inappropriate Corpus is to help the evaluator discover why a student may have made a particular error. Therefore, it contains texts that would not be deemed suitable parallel texts because they have a different skopos than that of the target text. One way in which the texts may differ from the target text is in terms of subject matter. Even subject fields that are related (e.g. they may be different subfields of a more general field) may have different conventions in their specialized languages. The DVD Inappropriate Corpus contains texts that are from the general subject field of optical storage technology, as well as texts dealing with highly specialized types of DVDs, such as DVD-RAMs and SD-DVDs.

Another way in which texts in the Inappropriate Corpus differ from the source text is in terms of text type. The source text was taken from a popularized science magazine, but the texts in the Inappropriate Corpus include technical reports, standards documents, Internet FAQs and advertisements.

A third type of inappropriate text that can be found in the Inappropriate Corpus is a text that dates from a different time period than the source text. The DVD inappropriate corpus includes a number of texts from 1995, which, given the fast-moving pace of development in the field, can be considered to be significantly older than the source text, which is dated 1999.

The Inappropriate Corpus can be used to further investigate student choices that do not appear in the Quality or Quantity Corpus. For example, one student expanded the acronym DVD into the term 'digital video disc'. A search in the Quantity Corpus revealed that in recently written texts, DVD is used to refer to a 'digital versatile disc'; however, a search in the Inappropriate Corpus revealed that when the 
technology was first introduced, DVD did in fact refer to 'digital video disc', but as the capabilities of the technology were increased, the name was switched to 'digital versatile disc'.

\section{Concluding Remarks}

The main aim of this article has been to develop a more objective approach to evaluating translations in an academic setting. It proposes a general approach to designing an Evaluation Corpus that can be used to help translator trainers evaluate student translations and provide more objective feedback. It then describes how evaluators can use corpus analysis tools to exploit an Evaluation Corpus, extracting information that could assist them with their evaluation task. The use of an Evaluation Corpus as a resource for evaluating translations offers a number of advantages over conventional resources. Its considerable size and electronic form mean that evaluators have easy access to a wealth of authentic examples that provide a common evaluative framework that can be consulted by both evaluator and student. The Evaluation Corpus is not, however, a panacea. A corpus should not be seen as a replacement for competence and critical judgement on the part of evaluators, but rather as an aid to help them make sound and objective judgements. The approach described here is corpus-based, but not corpus-bound.

As researchers such as Hönig (1998: 14) have stressed, where translation evaluation is concerned, a speculative element will remain and has to be admitted. It is unlikely that a method that will allow translator trainers to evaluate student translations in a completely objective manner will ever be devised. Nevertheless, this article has demonstrated that adopting a corpus-based approach can significantly reduce the subjective element in translation evaluation, and that this will benefit both evaluators and students.

\subsection{Future Developments}

The Evaluation Corpus described here was designed to assist with the evaluation of a translation that had the same skopos as the source text. It is also possible to design corpora that can assist with evaluation in cases where the target text has a different skopos than the source text. In such cases, it would not be worthwhile compiling a Comparable Source Corpus, but the other three subcorpora (Quality Corpus, Quantity Corpus and Inappropriate Corpus) could all be designed according to criteria that correspond to the skopos of the target text. For example, if students are asked to translate a technical report as if for publication in a popularized science magazine, the texts in the Quantity Corpus would contain texts from popularized science magazines rather than from technical reports, while a technical report might be included in the Inappropriate Corpus along with other texts that have different skopoi.

As explained in section 4, the techniques used for extracting useful information from corpora will differ from language to language and from subject field to subject field. In addition, more sophisticated extraction techniques can be developed for use on corpora that have been part-of-speech tagged or annotated in other ways. Further work is required to develop techniques and methodologies, both generic and specific, which can be used by evaluators and translators to exploit corpora more fully. 
Finally, and perhaps most importantly, as pointed out by Pym (1992: 283), the analysis of translation errors inevitably leads to an analysis of translation teaching. The Evaluation Corpus has proved to be a useful resource for helping trainers to identify and correct errors in student translations, and the next logical step will be to investigate the potential of integrating such corpora more fully into the teaching process. As discussed in section 1, trainers should provide their students with feedback that is concrete and constructive. Bringing corpora into the translation classroom helps to raise students' interest in and awareness of specialized language helping them to become more independent learners. Preliminary research in the area of using corpora for translation teaching is already being undertaken by researchers and translator trainers such as Bowker (1999), Pearson (1999), and Zanettin (1998), and more work in this area is needed.

\section{ACKNOWLEDGEMENTS}

I would like to thank Mona Baker of UMIST (UK) and Keith Harvey of the University of East Anglia (UK) who provided constructive comments on an earlier version of the work described here. This research was funded in part by an Albert College Fellowship awarded by Dublin City University and by the Social Sciences and Humanities Research Council of Canada.

\section{NOTES}

1. Parallel texts are printed documents that have been produced independently in the target language, but which have the same communicative function as the translation that is being produced.

2. The corpus analysis software used to conduct the research described in this article is WordSmith Tools, which was developed by Mike Scott at the University of Liverpool and is distributed by Oxford University Press: <http://www1.oup.co.uk/elt/catalogu/multimed/4589846/4589846.html>.

3. It is possible to imagine other types of Evaluation Corpora that could be designed for use in different translation evaluation situations (e.g. evaluating literary translation), but they would likely have a different make-up than the Evaluation Corpus described here.

4. For instance, there is little point in constructing a Comparable Source Corpus when the source and target texts do not have the same skopos (i.e., if the target text is being produced for a different type of audience then there is no real point in trying to establish whether or not the source text is representative of its text type). Text type may also be a determining factor: although any text type has the potential to contain non-conventional terminology or style, some text types are more likely than others to display this type of creativity (e.g. highly technical texts that aim to communicate specialized knowledge in a clear and precise manner are less likely to exhibit creativity than more popularized, journalistic or literary texts). Finally, in cases where evaluators are dealing with a typically non-creative text type, they may feel that the time required to construct a Comparable Source Corpus would not result in a worthwhile pay off. Time invested in building corpora must always be weighed against their potential usefulness.

5. Many general language corpora contain hundreds of millions of words (e.g. the British National Corpus), but it is generally accepted that corpora intended for specialized applications can be smaller than those used for general language research (Engwall 1994: 51).

6. For example, texts can be extracted from CD-ROMs or the WWW using keyword searches and other limiting parameters such as dates or text types. See section 4.3 for a brief description of how the DVD Quantity Corpus was compiled.

7. It is also possible to design an Evaluation Corpus to help evaluate a translation whose skopos differs from that of the source text (see section 5).

8. The British National Corpus can be consulted free of charge via the World Wide Web at: <http:// info.ox.ac.uk/bnc >. 


\section{REFERENCES}

BAKer, M. (1997): “Corpus-based Translation Studies: The Challenges that Lie Ahead," Terminology, LSP and Translation: Studies in Language Engineering in Honour of Juan C. Sager (H.L. Somers, ed.), Amsterdam, John Benjamins, pp. 175-186.

Bowker, L. (1999): "Exploring the Potential of Corpora for Raising Language Awareness in Student Translators," Language Awareness, 8-3/4, pp. 160-173.

Engwall, G. (1994): "Not Chance but Choice: Criteria in Corpus Creation," Computational Approaches to the Lexicon (B. T. S. AtKins and A. ZAmpolli, eds), Oxford, Oxford University Press, pp. 49-82.

Fraser, J. (1996): “Professional versus Student Behaviour," Teaching Translation and Interpreting 3: New Horizons (C. Dollerup and V. Appel, eds), Amsterdam, John Benjamins, pp. 243-50.

Hatim, B. and I. Mason (1997): The Translator as Communicator, London, Routledge.

HöNig, H.G. (1998): "Positions, Power and Practice: Functionalist Approaches and Translation Quality Assessment," Translation and Quality (C. SснёFfner, ed.), Clevedon, Multilingual Matters, pp. 6-34.

Kenny, D. (1998): “Creatures of Habit? What Translators usually Do with Words," Meta, 43-4, pp. 515-523.

Kussmaul, P. (1995): Training the Translator, Amsterdam, John Benjamins.

Larose, R. (1998): «Méthodologie de l'évaluation des traductions», Meta, 43-2, p. 163-186.

Louw, B. (1993): "Irony in the Text or Insincerity in the Writer? The Diagnostic Potential of Semantic Prosodies," Text and Technology: In Honour of John Sinclair (M. BAKer, G. Francis and E. Tognini-Bonelli, eds), Amsterdam, John Benjamins, pp. 157-176.

McMillan, E. N. (1987): "Recruitment and Retention of Staff and Freelance Translators: Experience at One International Agency," Translation Excellence: Assessment, Achievement, Maintenance (M.G. Rose, Ed.), Binghamton, SUNY, pp. 87-92.

Pearson, J. (1999): “Genes Go Wild in the Countryside: Using Corpora to Improve Translation Quality, Teanga, 18, pp. 71-83.

- (2000): "Surfing the Internet: Teaching Students to Choose their Texts Wisely," Rethinking Language Pedagogy from a Corpus Perspective (L. Burnard and T. McEnery, eds), Frankfurt, Peter Lang, pp. 235-239.

Рyм, A. (1992): “Translation Error Analysis and the Interface with Language Teaching," Teaching Translation and Interpreting: Training, Talent and Experience (C. Dollerup and A. LoddegaArd, eds), Amsterdam, John Benjamins, pp. 279-288.

SChäffner, C. (1998): "Parallel Texts in Translation," Unity in Diversity? Current Trends in Translation Studies (L. Bowker, M. Cronin, D. Kenny and J. Pearson, eds), Manchester, St. Jerome, pp. 83-90.

Summers, D. (1993): “Longman/Lancaster English Language Corpus - Criteria and Design," International Journal of Lexicography, 6-3, pp. 181-208.

Williams, I. A. (1996): “A Translator's Reference Needs: Dictionaries or Parallel Texts?,” Target, 8(2), pp. 275-299.

Zanettin, F. (1998): “Bilingual Comparable Corpora and the Training of Translators," Meta, 434, pp. 616-630.

\section{APPENDIX}

Brief: Translate this text as if for publication in a popularized science magazine (e.g. New Scientist).

\section{Le DVD tient ses promesses}

Il va envoyer au tapis CD-Rom, CD audio et VHS. Lui c'est le DVD, le disque numérique multiusage.

Premier enfant d'un accord entre géants de la micro-informatique et de la vidéo, le DVD, un nouveau standard, propose une capacité de stockage exceptionnelle, équivalent à 3000 disquettes de 1,4 Mo ou à plus de sept CD-Rom! 
Physiquement, il ressemble à s'y méprendre à un disque compact, mais il le surpasse en quantité d'information. Comme le CD audio, le DVD est lu par un faisceau laser qui balaie les pistes du disque percées d'une infinité de trous, porteurs de l'information binaire. La différence entre DVD et CD réside dans la taille des trous: $0,83 \mathrm{~mm}$ pour le $\mathrm{CD}, 0,40 \mathrm{~mm}$ pour le DVD, et la distance entre les pistes (respectivement $1,60 \mathrm{~mm}$ et $0,74 \mathrm{~mm}$ ). Cette réduction multiplie par trois la densité de données enregistrables par couche, permettant au DVD de stocker 4,7 Go sur une face et jusqu'à 17 Go sur des modèles à venir double face et double couche!

Le DVD-Rom est un super-CD-Rom. Lu sur un micro-ordinateur, il regroupe sur un seul support l'équivalent de cinq à sept CD-Rom, évitant ainsi de fastidieux changements de disques lors de la consultation d'encyclopédies ou au cours d'un jeu.

Source: Sciences et Avenir, février 1999 